disabled children $(\mathrm{p}<0.001)$, prosthetics, orthotics - 38.74 $\pm 3.27 \%(\mathrm{p}<0.001)$.

$32.43 \pm 3.14 \%$ of disabled children in need received sanatorium-resort treatment, $30.18 \pm 3.08 \%$ are currently queuing for a voucher. For various reasons, this type of rehabilitation was abandoned by $24.32 \pm 2.88 \%$, and $3.60 \pm 1.15 \%$ of patients (all $\mathrm{p}<0.001)$ contraindicated at the time of the ticket.

\section{P314 LEADING DISABILITIES IN THE STATE OF HEALTH AS A SIGN OF REDUCING THE QUALITY OF LIFE OF CHILDREN WITH DISABILITIES IN THE CITY'S CHILDREN'S POLYCLINIC}

\begin{abstract}
${ }^{1,2}$ Konstantin Shapovalov, 'Larisa Shapovalova*, ${ }^{2}$ Tatyana Yastrebtseva, ${ }^{2}$ Olga Toropova, ${ }^{2}$ Lyudmila Kantsarina, ${ }^{2}$ Evgeniya Kostareva. 'State Education Agency of Additional Professional Education of Republic of Komi 'Komi Republican Institute for Development of Education', Syktyvkar, Russian Federation; 'State Budget Agency of Health of the Republic of Komi 'Syktyvkar children's clinic ??3', Syktyvkar, Russian Federation
\end{abstract}

\subsection{6/archdischild-2019-epa.663}

The nature and severity of leading disabilities in health status of children with disabilities have a decisive influence on quality of their lives according to their physical and psychosocial characteristics.

The analysis of structure and frequency of leading limitation of vital activity instate of health of 1611 disabled children in 2011-2018 is carried out. in contingent of patients.

Seven major life limitations in the health status of children with disabilities were identified: 1) Reduced ability to selfcare: to manage physiological functions; to maintain personal hygiene; to perform daily household activities; to eat; 2) Reduced ability to move independently: to walk; to overcome obstacles; to move; to maintain balance when moving; to maintain balance when resting or changing body position; to use transport; 3) Reduction of the ability to orientate: to adequately perceive the situation and assess the situation; to determine location in time and space; 4) Reduced ability to communicate: to understand and express thoughts through language; to establish contacts; to listen; to see; 5) Reduction in the ability to control one's behavior: to be aware of oneself; to understand, interpret and cope with the situation; 6) Reduction of the ability to learn: to perceive, memorize, assimilate and reproduce knowledge; to master skills and abilities; 7) Reduced ability to work.

The leading limitation of bility to self-care was established in 581st disabled children (I rank, 36.06 $3.38 \%$ of patients). On the II rank place - the leading restriction of the ability to self-movement $-32.59 \pm 3.30 \%$. Much less frequently, the leading limitation of the ability to communicate is established $13.22 \pm 2.39 \%$ and the leading limitation of the ability to learn - patients $12.97 \pm 2.37 \%$ (all $\mathrm{p}<0.001$ ). The two subsequent $\mathrm{V}$ and VI ranking places respectively occupied the leading limitations of the ability to orientate $(2.54 \pm 1.11 \%, t=2.288)$ and the ability to control one's behavior $(1.99 \pm 0.98 \%, t=2.031)$. The leading limitation of ability to work did not exceed 0.63 $\pm 0.56 \%(\mathrm{t}=1.125)$.

The frequency of leading self-service limitation is 46.99 \pm 3.31 per 10,000 contingent of children and is 1.11 times higher than that of independent movement (42.46 \pm 3.48$)$, 2.73 times the ability to communicate $(17,23 \pm 2.66)$ and 2.78 times the ability to learn $(16.90 \pm 2.64)$. The leading restriction of the ability to orientate $(3.32 \pm 1.26)$ and the ability to control one's behavior $(2.59 \pm 1.12)$ were set respectively 14.15 and 18.14 times less than the leading restriction of the ability to self-service.

\section{P315 MEDICAL SUPPORT OF COMPLIANCE WITH THE STANDARDS OF PHYSICAL CULTURE AND SPORTS COMPLEXES BY A CONTINGENT OF PATIENTS OF THE CITY CHILDREN'S CLINIC AS A MARKER OF THE PHYSICAL DEVELOPMENT OF CHILDREN AND ADOLESCENTS OF THE SUBARCTIC TERRITORY}

\begin{abstract}
${ }^{1,2}$ Konstantin Shapovalov, ${ }^{1}$ Larisa Shapovalova*, ${ }^{2}$ Marina Zaboeva, ${ }^{2}$ Olga Chicherova, ${ }^{2}$ Natalya Nelipovich, ${ }^{2}$ Oksana Saitova. 'State Education Agency of Additional Professional Education of Republic of Komi 'Komi Republican Institute for Development of Education', Syktyvkar, Russian Federation; ${ }^{2}$ State Budget Agency of Health of the Republic of Komi 'Syktyvkar children's clinic 回了', Syktyvkar, Russian Federation
\end{abstract}

\subsection{6/archdischild-2019-epa.664}

Medical support of compliance with standards of physical culture and sports complexes is carried out on basis of established regulatory documents.

In SBAH RK 'SCC $\square 3$ ', patients aged 6-17 years who wish to take part inimplementation of standards are subject to examination.

The provision of medical assistance in implementation of standards includes the organization of: primary medical and specialized medical care in order to issue admission to implementation of standards to individuals who wish to take part in implementation of standards and the provision of primary medical and ambulance services, including emergency specialized medical assistance in implementation of standards to all participants.

Admission to implementation of the standards of students of educational institutions of preschool and general secondary education is carried out on basis of assigning the child to the main medical group for physical training by pediatricians of medical organizations.

If a minor citizen who wants to be tested, has a disability or a preparatory medical group for physical training, he is sent to the doctor in sports medicine (specialty 'medical and sports medicine').

The purpose of examining a doctor in sports medicine is to evaluate the response of the cardiovascular system to an increase in load and to determine the possible passing of testing in the relevant group. Conclusion with the decision on admission in this case is made by a doctor in sports medicine.

In the clinic in the 2016-2018 years. 807 children applied for examination, of which 787 were allowed to pass sports standards $(97.52 \pm 0.30 \%)$, corresponding to the years 2016 -

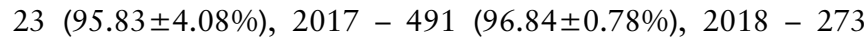
$(98.91 \pm 0.62 \%)$. In the structure of admitted children $13-15$ years old (31.00\%) and 11-12 years old (25.41\%) prevailed over other age groups 9-10 years old (19.95\%), 16-17 years old $(12.58 \%)$ and $6-8$ years $(11.06 \%)$.

If in 2016 only 24 people applied for certification, then in the next 2017 their number increased to 507, that is, 21.13 times. In this case, all patients were divided into three medical groups: the main - 443, preparatory - 52 (of which 4 children were not admitted) and special -12 .

Of the 807 children and adolescents examined over 3 years, the main medical group for physical training was established $87.73 \pm 1.15 \%$ of those examined, preparatory -10.78 
$\pm 1.09 \%$, of which $9.79 \pm 1.05 \%$ were admitted to surrender, and the special medical group determined $1.49 \pm 0.43 \%$ of children and adolescents (all $\mathrm{p}<0.001$ ).

\section{P316 GENERAL DISABILITY OF PATIENTS OF THE CITY CHILDREN'S POLYCLINIC OF THE SUBARCTIC TERRITORY}

\begin{abstract}
${ }^{1,2}{ }^{2}$ Konstantin Shapovalov*, ${ }^{*}$ 'Larisa Shapovalova, ${ }^{2}$ Tatiana Yastrebtseva, ${ }^{2}$ Marina Gorbitskaya, ${ }^{2}$ Natalya Semyannikova, ${ }^{2}$ Ksenia Avtushina. ${ }^{1}$ State Education Agency of Additional Professional Education of Republic of Komi 'Komi Republican Institute for Development of Education', Syktyvkar, Russian Federation; ${ }^{2}$ State Budget Agency of Health of the Republic of Komi ' Syktykar children's clinic [3]', Syktyvkar, Russian Federation
\end{abstract}

10.1136/archdischild-2019-epa.665

Childhood disability is a major marker of health status of the child population and prospects for its social well-being.

The analysis of diseases that caused the occurrence of disability in 710 disabled children was conducted. State Budget Agency of Health of Republic of Komi 'Syktyvkar children`s clinic 53', who were disabled in 2016-2018. Control group consisted of 901 patients of 'SCC $\square 3$ ' who were disabled in 2011-2015.

Determined the ranking of diseases that caused the emergence of disability in children with disabilities, their structure and frequency per 10,000 contingent patients of clinics

When working on material used methodological approaches: systemic, integrated, integration, functional, dynamic, process, regulatory, quantitative, administrative and situational. Used methods: historical, analytical and comparison. The following techniques were used: grouping, absolute and relative values, average values, detailing and generalization. The significance of differences in quantitative characteristics between groups with a normal distribution of quantitative variables was calculated using Student's t-criteria for independent samples.

The formed indicators of the general disability of the contingent of patients of the urban children's clinic of the regional center of the subarctic territory is a statistical tool of everyday use for the objectification of the rehabilitation process, their comparative evaluation and determination of the strength and means of a medical institution for its successful maintenance.

For period from 2011-2018. total (widespread) disability in 'SCC 03 ' increased in absolute terms from 166 to 261 people, that is, 1.57 times and, correspondingly, with a growth rate of $157.23 \%$. The frequency of primary disability increased 1.34 times from 118.69 per 10,000 patients to 159.92, while the growth rate was $134.73 \%$. With outpacing growth of primary disability over general trend of further growth in number of disabled children will increase.

Based on the calculations in 2019, no less than 86-90 disabled children are expected, who will have VI G00-G99 Diseases of nervous system $(36.33-35.44 \%, \%$ in overall structure and frequency 57.59) as leading pathology. -52.41 per 10,000 patients). As a result of examinations, 55-53 children with XVII Congenital anomalies, chromosomal disorders Q00-Q99 (23.46-22.25\%, frequency - 33.70-32.09) will be identified as disabled; 31-26 children with IV Endocrine Disorders, eating disorders and metabolic disorders E00-E90 (11.88-10.85\%, frequency 18.99-15.64); II neoplasms C00-D48 (10.34$9.86 \%$, frequency 16.54-14.22); VIII Diseases of the ear and mastoid H60-H95 (9.30-9.00\%, frequency 12.12-11.64); 9-8 children with XIII Diseases of the musculoskeletal system and connective tissue M00-M99 (4.28-3.83\%, frequency - 6.135.58); VII. Diseases of the eye and adnexa H00-H59 (3.60$3.45 \%$, frequency $5.51-4.69$ )

\section{P317 THE STUDY OF AVAILABLE AND PROMISING METHODS OF DIAGNOSIS, CORRECTION AND TREATMENT OF FETAL OVARIAN TUMORS (CYSTS) IN THE FETUS, WITH MAXIMUM PRESERVATION OF THE FUNCTION OF THE REPRODUCTIVE SYSTEM. THE STUDY WAS FORMED BY THE LEADING DOCTORS OF THE PERINATAL CENTER OF THE ST. PETERSBURG STATE PEDIATRIC MEDICAL UNIVERSITY}

Anna Taits*, Dmitriy Ivanov, Anna Malisheva, Ivan Errshov. The Perinatal Center of the St Petersburg State Pediatric Medical University, St. Petersburg, Russian Federation

\subsection{6/archdischild-2019-epa.666}

The most frequent complication is the twisting of the legs of an ovarian cyst in $61 \%$ cases, intestinal obstruction in 3\%. Twisting an ovarian cyst can spontaneously regress, but it can also cause embedding the appendages themselves and their migration to different parts of the abdominal cavity and cause sudden death of the newborn. Indications for surgical treatment are: the size of a cyst is more than $4 \mathrm{~cm}$, signs of torsion, a migrating cyst.

Materials and methods In our study, there were 20 girls born on the term from 26 to 41 weeks of gestation, in 7 cases through cesarean section, and in 13 cases through the birth canal. 15 girls from the group of newborns diagnosed with prenatal from 30 to 36 weeks of pregnancy were hospitalized in the department of pathology of newborns and premature babies in the period from 1 to 5 days of life and 3 girls of infancy in 1-1.5-2 months of life, due to the fact that the diagnosis is made in a month of life. The examination of the girls included anamnesis, general clinical studies, an ultrasound examination of the pelvic organs and the abdominal cavity was performed. In 11 cases out of 20 additional multispiral computed tomography was required, as well as histological examination of the surgical material. Surgical treatment was performed on all girls with laparoscopic transumbulial minilaparotomy. All interventions were performed as far as possible with maximum preservation of ovarian tissue. In 12 girls, adnexectomy was performed due to necrotic changes of the appendages as a result of torsion of $45 \%$ and in combination with adhesive disease 15\%. Ovariocytectomy was performed in 6 cases. And in 2 cases enterokistoma was detected. According to the morphological assessment of ovarian lesions in newborns, in most cases there are simple follicular ovarian cysts with hemorrhages, calcification and necrosis during torsion.

Conclusions Particular attention should be paid to quality prenatal diagnosis with a detailed assessment of all criteria for simple and complex ovarian cysts and the question of the possible use of fetal surgery, which will facilitate the timely adoption of measures and prevent the occurrence of complications with subsequent loss of appendages. An obstetrician-gynecologist should be involved at all stages of the management and treatment of this category of patients from the moment of prenatal diagnosis. Surgical treatment of these patients should be carried out in specialized hospitals using high-tech methods. 